\title{
The association of racial attitudes and spiritual beliefs in post- apartheid South Africa
}

Timothy B. Smith

Brigham Young University, tbs@byu.edu

Christopher R. Stones

Rhodes University

Christopher E. Peck

Brigham Young University

Anthony V. Naidoo

University of Stellenbosch

Follow this and additional works at: https://scholarsarchive.byu.edu/facpub

Part of the African American Studies Commons, Counseling Psychology Commons, and the Religion Commons

\section{Original Publication Citation}

Smith, T. B., Stones, C. R., Peck, C., \& Naidoo, A. V. (2007). The association of racial attitudes and spiritual beliefs in post-apartheid South Africa. Mental Health, Religion, \& Culture, 10, 263-274.

\section{BYU ScholarsArchive Citation}

Smith, Timothy B.; Stones, Christopher R.; Peck, Christopher E.; and Naidoo, Anthony V., "The association of racial attitudes and spiritual beliefs in post-apartheid South Africa" (2007). Faculty Publications. 2024. https://scholarsarchive.byu.edu/facpub/2024

This Peer-Reviewed Article is brought to you for free and open access by BYU ScholarsArchive. It has been accepted for inclusion in Faculty Publications by an authorized administrator of BYU ScholarsArchive. For more information, please contact ellen_amatangelo@byu.edu. 
Running Head: RACIAL ATTITUDES AND SPIRITUAL BELIEFS

Smith, T. B., Stones, C. R., Peck, C., \& Naidoo, A. V. (2007). The association of racial attitudes and spiritual beliefs in post-apartheid South Africa. Mental Health, Religion, \& Culture, 10, 263-274.

The Association of Racial Attitudes and Spiritual Beliefs

in Post-Apartheid South Africa

Timothy B. Smith

Brigham Young University

Christopher R. Stones

Rhodes University

Christopher E. Peck

Brigham Young University

Anthony V. Naidoo

University of Stellenbosch

Correspondence concerning this manuscript should be sent to Timothy B. Smith, Ph.D., 340N

MCKB, Department of Counseling Psychology, Brigham Young University, Provo, UT 84602,

USA. Phone 1-(801) 422-1331, fax 1-(801) 422-0198, email: Tim_Smith@byu.edu 
The Association of Racial Attitudes and Spiritual Beliefs

in Post-Apartheid South Africa

\begin{abstract}
Previous research has investigated the complex association between religious beliefs and racism. Many studies have found that fundamentalist religious beliefs are positively associated with racial prejudice among European and European American populations. However, few studies have examined if this association is found in other cultures or if the association also characterizes spiritual beliefs. Data from 493 South African university students from three racial backgrounds revealed significant differences among the groups. A positive association between fundamentalism and racial prejudice was found among participants, but general spiritual beliefs were negatively associated with racist attitudes. The results emphasize the need to address contextual factors that influence the association between religious beliefs and racism within a given culture.
\end{abstract}

Key Words: cross-cultural studies; ethnic identification; prejudice; race, ethnicity; religiosity 
The Association of Racial Attitudes and Spiritual Beliefs

in Post-Apartheid South Africa

Few topics are as complex as the association of religion and racism, especially in societies with such profound and pervasive legislated racial power differentials as South Africa. Religious teachings were used (misused) to justify racial subjugation and tyranny under colonialisation and later under apartheid (e.g., de Gruchy, 1997). Ironically, religious doctrines were also instrumental in the abolition of slavery in South Africa in the 1820s, and they have provided inspiration for many socio-political movements that have fought for racial equality and liberation since that time. Religion has thus both contributed to oppression on the one hand and to self-determination and positive inter-group interactions on the other. In addressing the complex and contradictory associations between religion and racial prejudice, Gordon Allport's observation of over 50 years ago still appears timely: "Some people say the only cure for prejudice is more religion; some say the only cure is to abolish religion" (1954, p. 444).

The association of racism and religiosity is complex in part because both racism and religiosity are influenced by a host of other factors: Individuals’ religiousness and racial attitudes reflect the influence of educational attainment, socio-economic conditions, culture, and any other variable that reinforces or challenges existing social structures. Moreover, racial attitudes and religiousness indirectly influence one another through such constructs as social values, nationalism, and ethnic/cultural identity. To complicate matters, in contemporary society many individuals perceive spirituality as being much more relevant to their lives than religion, yet scholarship in the field has generally failed to addresses spirituality rather than religiosity. The complex relationship between spirituality and intergroup relations may hold important implications for reconciliation as individuals and collectives attempt to move toward a more 
united future in South Africa after centuries of racial conflict. The following sections review recent research relative to association between spirituality and racism followed by more specific information regarding racism and spirituality in the South African context.

Spirituality and Racism

Whereas the term religion refers to an institutionalized set of doctrines and rituals practiced by a distinct group of people, the term spirituality usually refers to individuals’ transcendental or other-worldly beliefs and experiences that do not necessarily involve religion (Smith \& Richards, 2005). Most social psychological research has investigated the association of religious involvement, not spirituality, to racial prejudice. In this regard, although several researchers have found a positive association between religious involvement and racial prejudice (Altemeyer, 2003; Dreyer, Pieterse, \& Van Der Ven, 2002; Duriez \& Hutsebaut, 2000; Jackson \& Hunsberger, 1999), the majority of research studies have concluded that the two constructs are not consistently related to one another (Smith \& Richards, 2005). The association appears to be context specific and dependent on the type of religiousness measured, opening the door for researchers to consider specific aspects of spirituality that are not necessarily based on public religious involvement.

For example, a study by Jackson and Hunsberger (1999) showed how religion may not be as significant in relation to prejudice as personal spiritual beliefs and intergroup dynamics. They found generally that, "religion per se is not the problem; rather, the difficulty is with the way in which some people are religious” (p. 510). Because formal organizations such as religious congregations by definition create in-group vs. out-group dynamics, it is not surprising that research has revealed that non-believers show prejudice against believers and religious individuals show preference for other religious individuals (Jackson \& Hunsberger, 1999). 
Altemeyer (2003) demonstrated in a similar study that arbitrary group members favored their ingroup over the out-group. Thus, group dynamics and in-group characteristics associated with a religious organization generally appeared to be culpable relative to increasing racial prejudice, but those same dynamics would not necessarily apply to spiritual beliefs, which are more personal and less institutionalized.

Consistent with these findings of the effects of group dynamics is the large body of research that has shown dogmatic, fundamentalist adherence to personal beliefs to be positively associated with racist attitudes (Altemeyer, 2003; Jackson \& Hunsberger, 1999; Dobratz, 2001; Duriez \& Hutsebaut, 2000). “One’s creed per se does not particularly associate with such prejudice, but the attitude that one's beliefs are the fundamentally correct, essential, inerrant ones is associated with bigotry" (Altemeyer, 2003, p. 19). The relationship between spirituality and racism is therefore moderated by the historic-cultural context and by the degree of dogmatism with which the beliefs are held.

Given these findings, it is still unclear why individuals who strongly adhere to spiritual beliefs that ostensibly promote principles such as inter-personal unity and tolerance are not less racist - so long as they do not hold to those beliefs in a dogmatic fashion. Studies have assessed several aspects of non-dogmatic spiritual beliefs, such as intrinsic vs. extrinsic religious motivations and God image. However, these aspects of spirituality have typically been considered separately (one variable per study) with no consistency in how they are measured across studies (Duriez \& Hutsebaut, 2000). It therefore appears that the research literature could benefit from multidimensional assessment of spirituality. A study that assesses fundamentalism but that also includes general spiritual beliefs as well as spiritual alienation (a construct that is increasingly relevant in contemporary society) could provide a more accurate understanding of 
Racial Attitudes and Spiritual Beliefs 6

how spirituality may be associated with racial tolerance or racial biases. Such information could be particularly useful in contexts where racial issues and racism are pervasive, such as in South Africa.

Racism in South Africa

There is a general consensus that racism in South Africa is alive, well, and in some cases on the rise (Carrim, 2000; Dawes \& Finchilescu, 2002; Kruss, 2001; Singh-Pillay \& Collings, 2004; Slabbert, 2001). Despite the remarkable political changes since the first democratic elections in 1994 and subsequent attempts to improve national unity, there have been mixed and often marginal effects upon intergroup relations. Singh-Pillay and Collings (2004) found that a significant proportion of respondents (56\%) had experienced recent episodes of discrimination “despite the social and political changes that have occurred in South Africa in the past 10 years" (p. 6). Indeed, racism "remains an insidiously destructive force” in the country (Slabbert, 2001, p. 131). It short, it will take great efforts to overcome centuries of discrimination and the continued abuse of power across racial lines (Dawes \& Finchilescu, 2002).

Despite the continuing problems related to racism in South Africa, there are cases, especially in public schools and universities, where few people are talking about race, sometimes even affirming that “we don’t have a problem here” (Carrim, 2000, p. 33). So why might the schools and universities attempt to conceal negative racial attitudes? Carrim contends that this culture of denial is related to at least three kinds of fear: (1) fear of losing privilege; (2) fear of continuing with the ways of the past; and (3) fear of civil strife. Another author corroborates this denial of racism by stating, "Whatever the reasons, South African society’s pre-occupation with not being pre-occupied with 'race' and racism provides an initial impetus for continued critical research, theorizing and study into these phenomena” (Stevens, 2003, p. 192). Clearly, 
continued monitoring of racial attitudes in South Africa appears warranted, particularly among the young and among university students, who represent the future leaders of the nation. Spirituality in South Africa

In the remarkable history of race relations in South Africa, spiritual beliefs have played a significant role in both perpetuating and combating racism (Sparks, 1990). Spiritual beliefs were openly used by South African Whites to oppress other racial groups (e.g., public claims by the former South African government that the Bible sanctioned apartheid, the systematic separation of races). In contrast, holding firm to spiritual beliefs aided Blacks and so-called Coloureds (South Africans of mixed-race/Asian ancestry) to unite in withstanding, and eventually dismantling, systems of racial oppression, similar to how the spiritual beliefs of African Americans were instrumental in the Civil Rights movement in the United States. Therefore, when considering the association of spiritual beliefs to racial attitudes in South Africa, it is essential to also consider differences across racial groups.

Christianity is the dominant religion in South Africa, but there is no official state religion. The new South African Constitution provides for freedom of religion, and there is diversity within the predominantly Christian spiritual teachings and practices across the nation (Chidester, 1992). Over 4,000 African independent churches have emerged over the past several decades (Bureau of Democracy, Human Rights, and Labor, 2002). As one author has described it, "It is not as if this diversity is new, but a more open society has allowed it to show” (Cochrane, 2000, p. 448). Amidst the prominent changes of the South African spiritual landscape, with large religious institutions becoming less and less relevant compared to local churches and to intrapersonal spirituality, there is an increased need to attend to the impact of not only religious but spiritual influences - particularly as they relate to positive social and psychological 
outcomes. We agree with Bowen-Reid and Harrell (2002) that “although most work has focused on religious beliefs and ideologies, it is also important that efforts be directed toward understanding the underlying mechanisms of spirituality” (p. 34). Therefore, in the present study, we evaluated spiritual orientations with the understanding that these may be more relevant to the contemporary South African context than religious involvement per se.

Several recent studies have focused on South African spirituality and health outcomes (Nicholas \& Durrheim, 1995; Peltzer, 2002; Peltzer, Malaka, \& Phaswana, 2002). Overall the findings converge on a theme that Peltzer (2002) articulates: “There is ample evidence to demonstrate that [spiritual] beliefs and practices are associated with positive health behaviors" (p. 82). Important for the South African context, a study by Bowen-Reid and Harrell (2002) revealed spirituality as a positive buffer that decreases the stresses associated with racism. However, the association between spirituality and racist attitudes in South Africa is unclear and warrants additional explication.

The purpose of our study was therefore to evaluate how multiple dimensions of spirituality relate with racist attitudes in samples of South Africans from different racial groups. We sought to test the hypotheses that general spiritual beliefs would be negatively associated with racist attitudes but that spiritual alienation and fundamentalism would be positively associated with racist attitudes after controlling for participant-race. Because both spirituality and racial attitudes likely differ across racial groups, it was important to assess whether the participant's race moderated the results. We therefore evaluated the interaction between participant-race and spirituality with the hypothesis that the magnitude of the association between spiritual beliefs and racial attitudes would be strongest among South African Blacks and 
so-called Coloureds, who tend to report greater spirituality but less out-group racism relative to White South Africans (Smith \& Stones, 1999).

\section{Method}

\section{Participants}

A total of 563 adults attending two universities in South Africa were recruited from introductory social science classes. Participants were 69\% female, with 73\% reporting that they came from middle- or upper-middle-class socio-economic backgrounds. Participants consisted of 54\% Whites, 27\% Blacks, and 19\% so-called Coloureds; 70 participants did not report their race and were therefore excluded from the analyses. Participants originated from all South African provinces, with 24\% from the Western Cape, 22\% from the Eastern Cape, 20\% from Gauteng, and 15\% from KwaZulu Natal. Many participants (40\%) were first-year students, with the average age being 20.7 years.

\section{Measures}

In classroom settings participants completed a demographic questionnaire and measures of three aspects of spiritual orientation and two aspects of racial attitudes. The Subtle Racism Scale (SRS) (Duckitt, 1991, 1993) evaluates acceptance of inter-racial contact and the aspiration for equal status among all races (example item: "If all races mixed freely they would certainly live in peace”). The Anti-White Scale (AWS) (Duckitt \& Farre, 1994) was used to assess prejudice against White participation in the social, economic, and political contexts of South Africa and the perceived necessity for Whites to suffer retribution for the wrongs of Apartheid (example item: “The history of this country shows that most Whites do not deserve to be treated with respect”). Both the Subtle Racism Scale and the Anti-White Scale were specifically developed for use with South African populations, and both consist of 10 items answered on a 7- 
point Likert-type scale, with higher scores indicative of greater racial prejudice. Authors have reported acceptable reliability coefficients (ranging from .76 to .91) and acceptable content and construct validity estimates in studies using these two scales (Duckitt, 1991, 1993; Duckitt \& Farre, 1994). With the data collected in this study, the internal consistency coefficients were .61 with the Subtle Racism Scale and .72 with the Anti-White Scale.

To assess different aspects of spirituality, we administered items from the Multidimensional Spiritual Orientation Inventory (MSOI) (Richards, Morgan, \& Bergin, 1998). The MSOI was designed for ecumenical use with individuals from predominantly Christian backgrounds, although it contains no specific reference to Christianity or religion. Rather, items are worded in terms of general spiritual beliefs. Items are answered on a 5-point Likert-type scale, with higher values indicating greater endorsement of the item. Based on exploratory factor analyses of the items administered, we extracted three subscales from 32 MSOI items that assessed: (1) general spiritual beliefs (example item: “My spiritual beliefs are sacred to me”), (2) spiritual alienation (example item: “I feel like an 'outsider’ in my spiritual tradition”), and (3) fundamentalism (example item: "I am unwilling to consider the possibility that my spiritual beliefs might be wrong”). With data collected in the present study, the 19-item subscale assessing general spiritual beliefs yielded an internal consistency coefficient of .93; the 5-item subscale assessing spiritual alienation yielded an internal consistency coefficient of .74; and the 8-item subscale assessing fundamentalism yielded an internal consistency coefficient of .76. The three subscales were only moderately correlated with one another (absolute values of Pearson $r$ ranging from .23 to .41), indicating that they assessed different aspects of spirituality. Statistical Analyses 
In preliminary analyses to determine if there were differences across racial groups, we conducted two multivariate analyses of variance (MANOVAs), one for the two measures of racial attitudes and another for the three measures of spiritual orientation. To test the hypotheses of this study that spirituality will predict racial attitudes after controlling for participant-race, we conducted two regression models, one with the Subtle Racism Scale and another with the AntiWhite Scale. In both models, participants' race was entered into the first step of each model, with Black and so-called Coloured participants contrasted with White participants. The three measures of spiritual orientation were entered into the second step. To investigate the possibility that participant-race moderated the results, we entered the interaction between participant-race and spiritual orientation in a third step of the model. Significant interaction terms would indicate a moderating relationship.

Results

A MANOVA conducted across participant racial groups using the two measures of racial attitudes (SRS and AWS) reached statistical significance $\left(F_{(4,944)}=57.1\right.$, Wilks lambda $=.65, p$ $<$.001). Subsequent oneway analyses of variance indicated significant differences on both the Subtle Racism Scale $\left(F_{(2,481)}=45.5, p<.001\right)$ and Anti-White Scale $\left(F_{(2,497)}=70.6, p<.001\right)$. A post hoc analysis (Scheffé) on the Subtle Racism Scale revealed that Black participants $(M=$ 27.1, $S E=.66)$ scored lower than so-called Coloured participants $(M=30.4, S E=.81)$ and that both these groups scored significantly lower than White participants $(M=35.2, S E=.54)$, indicating a greater tolerance for interracial integration among them compared to White participants. On the Anti-White Scale, the opposite trend was found, with Black participants ( $M$ $=20.8, S E=.83)$ scoring higher than so-called Coloured participants $(M=16.2, S E=.66)$ and 
with both of these groups scoring higher (indicating greater bias against Whites) than White participants $(M=11.7, S E=.37)$.

A second MANOVA conducted across participant race with the three measures of spiritual orientation also reached statistical significance $\left(F_{(6,866)}=6.4\right.$, Wilks lambda $=.92, p<$ .001). Subsequent univariate analyses indicated significant differences on the measures of general spiritual beliefs $\left(F_{(2,449)}=8.9, p<.001\right)$, fundamentalism $\left(F_{(2,459)}=16.2, p<.001\right)$, and spiritual alienation $\left(F_{(2,469)}=4.4, p=.01\right)$. Post hoc analyses (Scheffé) revealed that on the measure of general spiritual beliefs both Black $(M=92.6, S E=1.1)$ and so-called Coloured participants $(M=93.6, S E=1.1)$ scored significantly higher than White participants $(M=87.3$, $S E=1.1)$. On the measure of fundamentalism Black participants $(M=32.4, S E=.52)$ scored higher than White participants $(M=28.3, S E=.44)$, and on the measure of spiritual alienation Black participants $(M=9.2, S E=.36)$ scored lower than White participants $(M=10.3, S E=$ $.27)$.

Prior to conducting the regression models, we analyzed the bivariate correlations among the measures (Table 1), with the observed patterns generally conforming to hypothetical expectations. To evaluate differences in the magnitude of these associations after controlling for participant race, we conducted two separate regression models. The first regression model predicted Subtle Racism Scale scores from participants’ race and spiritual orientation. Black and so-called Coloured participants were collapsed into one group and entered into the regression model as a contrast with White participants. As was expected based on the results of the MANOVA reported above, participants' race explained a moderate amount of variance in Subtle Racism Scale scores $\left(\mathrm{R}_{(1,416)}^{2}=.158\right.$, adjusted $\left.\mathrm{R}^{2}=.156, F=77.9, p<.001\right)$ and the addition of the three spiritual orientation variables in the second step resulted in a statistically significant 
increase in explained variance $\left(\mathrm{R}^{2}{ }_{(3,413)}=.191\right.$, adjusted $\mathrm{R}^{2}=.183$, change in $\mathrm{R}^{2} F=5.6, p=$ .001). As may be seen in Table 2, when the measures of spiritual orientation were added in the second step, Spiritual Alienation and Fundamentalism predicted Subtle Racism Scores but Spiritual Beliefs did not. The third step of the model that added the interaction between the three spiritual orientation measures and race did not significantly explain additional variance in Subtle Racism Scores $\left(\mathrm{R}^{2}(3,410)=.204\right.$, adjusted $\mathrm{R}^{2}=.190$, change in $\left.\mathrm{R}^{2} F=2.2, p=.08\right)$. Contrary to our hypothesis, this finding indicated that participant race did not moderate the association between the measures of spiritual orientation and the Subtle Racism Scale.

The second regression model predicted Anti-White Scale scores from participants’ race and spiritual orientation. Participants’ race explained a moderate amount of variance in AntiWhite Scale scores $\left(\mathrm{R}_{(1,423)}^{2}=.167\right.$, adjusted $\left.\mathrm{R}^{2}=.165, F=84.5, p<.001\right)$ and the addition of the three spiritual orientation variables in the second step resulted in a statistically significant increase in explained variance $\left(\mathrm{R}^{2}{ }_{(3,420)}=.223\right.$, adjusted $\mathrm{R}^{2}=.215$, change in $\mathrm{R}^{2} F=10.1, p<$ .001). As may be seen in Table 3, when the measures of spiritual orientation were added in the second step, Spiritual Alienation and Spiritual Beliefs predicted Anti-White Scores but Spiritual Fundamentalism did not. The addition of the interaction terms in the third step of the model did not result in a statistically significant increase of the amount of variance explained $\left(\mathrm{R}^{2}(3,417)=\right.$ .228 , adjusted $\mathrm{R}^{2}=.215$, change in $\mathrm{R}^{2} F=1.0, p=.39$ ). Contrary to our hypothesis, the association between Anti-White Scale scores and the measures of spiritual orientation was not moderated by participant race.

\section{Discussion}

There many are reasons to suspect that spiritual beliefs should be relevant to racial attitudes and racism (Smith \& Richards, 2005). The association between spiritual beliefs and 
racism is particularly salient in nations with prolonged racial divisions, such as South Africa. Given historical differences in how spiritual beliefs have been used across South African racial groups to either promote or combat racism (Sparks, 1990), the present research explicitly examined differences in the association between spiritual beliefs and racism across racial groups. As expected, Blacks and so-called Coloured participants endorsed spiritual beliefs more than Whites, and they were also more likely to defend their spiritual beliefs compared to Whites, whose spiritual beliefs were more flexible. Given these significant racial differences regarding the level of personal commitment to spiritual beliefs, an important finding of this study was that participant-race did not moderate the association between spiritual beliefs and racism. Contrary to our hypothesis, differences in the magnitude of the association between spiritual beliefs and racism did not reach statistical significance across racial groups. This finding lends support to the assumption that with respect to inter-group relations, spiritual beliefs may share similar properties across distinct cultures.

Another contribution of this study concerned the relevance of spiritual beliefs. Because spiritual beliefs may be more salient to many individuals than religious beliefs (with some individuals endorsing spirituality but not necessarily religiosity), we purposefully used measures of spiritual orientation that did not reference religion. Previous research regarding racial attitudes has almost exclusively involved religious variables rather than spiritual variables. Thus we were particularly interested in determining if the measures of spiritual orientation used in this study were associated with racism. The findings of the present study lend support to the hypothesis that spiritual beliefs are associated with racial attitudes. Even when religious content is absent, the results obtained were similar to previous studies involving religious variables. 
However, the nature of the association between spiritual beliefs and racism depends upon the type of spiritual beliefs evaluated.

In this regard, general spiritual beliefs were not predictive of subtle racism scores but were significantly negatively associated with anti-White sentiment. In turn, spiritual alienation was significantly positively associated with both subtle racism and anti-White sentiment, and fundamentalism was positively associated with subtle racism but was not predictive of antiWhite sentiment. These results provide only partial support for the hypotheses that general spiritual beliefs would be consistently negatively related with racist beliefs and that spiritual alienation and fundamentalism would be consistently positively related with racist beliefs. Nevertheless, these results are generally consistent with previous research findings in which religious beliefs are either not associated with racism or are mildly negatively associated with racism, with religious fundamentalism typically positively associated with racism (Smith \& Richards, 2005).

In making these interpretations of the data, several limitations of this particular study need to be considered. First of all, this study employed a correlational design that could not address issues of causality. For example, it is not certain whether intrinsically pro-social individuals seek out spiritual beliefs and experiences that reinforce their own personal values or whether spiritual beliefs and experiences increase pro-social values among the general population (or both). Second, the data should not be generalized to populations outside of South Africa or even to the entire South African population. While the sample consisted of representatives from every province in the country, the participants were university students from predominantly middle- to upper-middle socioeconomic backgrounds, clearly different from other age groups, from non-students of similar age, and from the high percentage of Black South 
Africans who live in poverty. Third, one of the measures of racial attitudes used in this study, the Subtle Racism Scale, demonstrated below average internal consistency, which may have unduly impacted the analyses involving that measure. Fourth, many other factors associated with both spirituality and racism were not assessed in this study. Although the fact that we employed a multidimensional assessment of spiritual orientation and two measures of racial attitudes was a strength of the study, we did not evaluate such key factors as nationalism, congruence of behavior with spiritual beliefs, parental and peer-group influences, etc.

Furthermore, we did not evaluate subtle vs. overt racism, and we did not contrast the measures of spirituality with more traditional measures of religiousness. Taken together, these limitations qualify the data of the present study as exploratory until future research confirms or refutes the results obtained.

Overall, the findings of the present study lend support to the conclusion that the association between spiritual beliefs and racism depends upon the type of spiritual beliefs evaluated. Spiritual beliefs may benefit interracial relations when those beliefs are explicitly made salient to interracial relations but they may not when spirituality is seen in more abstract terms, devoid of implications for personal conduct or for the welfare of those with different backgrounds. As articulated by Allport (1954), the association between belief and bias depends upon what the beliefs are and how they are activated in relation to others. It remains for future research to continue to clarify the conditions that moderate and mediate the association between spiritual beliefs and racial prejudice across different cultures, with an aim to dismantle harmful social systems and beliefs promoted through the misuses of religion, such as apartheid in South Africa, that exist in less obvious forms in nearly every contemporary society. 


\section{References}

Allport, G. W. (1954). The nature of prejudice. Cambridge, MA: Addison-Wesley.

Altemeyer, B. (2003). Why do religious fundamentalists tend to be prejudiced? International Journal for the Psychology of Religion, 13, 17-28.

Bowen-Reid, T. L., \& Harrell, J. P. (2002). Racist experiences and health outcomes: An examination of spirituality as a buffer. The Journal of Black Psychology, 28, 18-36.

Bureau of Democracy, Human Rights, and Labor. (2002). International Religious Freedom Report 2002 [Online]. Available at: http://www.state.gov/g/drl/rls/irf/2002/13854.htm

Carrim, N. (2000). Critical anti-racism and problems in self-articulated forms of identities. Race Ethnicity and Education, 3, 26-44.

Chidester, D. (1992). Religions of South Africa. New York: Routledge.

Cochrane J. R. (2000). Religious pluralism in post-colonial public life. Journal of Church and State, 42, 443-465.

de Gruchy, J. W. (1997, December 17). Churches in South Africa: Giving account. Christian Century, 1180-1182.

Dawes, A., \& Finchilescu, G. (2002). What's changed? The racial orientations of South African adolescents during rapid political change. Childhood, 9, 147-165.

Dobratz, B. A. (2001). The role of religion in the collective identity of the White racialist movement. Journal for the Scientific Study of Religion, 40, 287-301.

Dreyer, D., Pieterse, H., \& Van Der Ven, J. A. (2002). Interreligious orientations among South African youth: expressions of religious identity. International Journal of Education and Religion, 2, 158-178. 
Duckitt, J. (1991). The development and validation of a subtle racism scale in South Africa. South African Journal of Psychology, 21, 233-239.

Duckitt, J. (1993). Further validation of a subtle racism scale in South Africa. South African Journal of Psychology, 23, 116-119.

Duckitt, J., \& Farre, B. (1994). Right-wing authoritarianism and political intolerance among Whites in the future majority-rule South Africa. The Journal of Social Psychology, 134, 735-741.

Duriez, B., \& Hutsebaut, D. (2000). The relation between religion and racism. Mental Health, Religion \& Culture, 3, 85-102.

Jackson, L. M., \& Hunsberger, B. (1999). An intergroup perspective on religion and prejudice. Journal for the Scientific Study of Religion, 38, 509-523.

Nicholas, L., \& Durrheim, K. (1995). Religiosity, aids, and sexuality knowledge, attitudes, beliefs, and practices of black South-African first-year university students. Psychological Reports, 77, 1328-1330.

Peltzer, K. (2002). Factor structure of religious problem coping styles in an African sample. Social Behavior and Personality, 30, 509-514.

Peltzer, K. (2002). Religiosity, religious coping ad health behavior among black students in South Africa. Studia Psychologica, 44, 75-83.

Peltzer, K., Malaka, D. W., \& Phaswana, N. (2002). Sociodemographic factors, religiosity, academic performance and substance abuse among first-year university students in South Africa. Psychological Reports, 91,105-113. 
Richards, P. S., Morgan, D., \& Bergin, A. E. (1998). Development of the Multidimensional Spiritual Orientation Inventory (MSOI). Unpublished manuscript, Brigham Young University, Provo, UT.

Roberts, R., Phinney, J., Masse, L., Chen, Y., Richard, R., Roberts, C., \& Romero, A. (1999). The structure of ethnic identity of young adolescents from diverse ethnocultural groups. Journal of Early Adolescence, 19, 301-322.

Singh-Pillay, N., \& Collings, S. J. (2004). Racism on a South African campus: A survey of students’ experiences and attitudes. Social Behavior and Personality, 32, 607-618.

Slabbert, A. (2001). Cross-cultural racism in South Africa - dead or alive? Social Behavior and Personality, 29, 125-132.

Smith, T. B., \& Richards, P. (2005). The integration of spiritual and religious issues in racialcultural psychology and counseling. In R. T. Carter (Ed.), Handbook of racial-cultural psychology and counseling: Theory and research (vol. 1). Pp. 132-160. Thousand Oaks, CA: Sage.

Smith, T. B., \& Stones, C. R. (1999). Identities and racial attitudes of South African and American adolescents: A cross-cultural examination. South African Journal of Psychology, 29, 23-29.

Sparks, A. H. (1990). The mind of South Africa. New York: Knopf.

Stevens, G. (2003). Academic representations of 'race’ and racism in psychology: Knowledge, production, historical context and dialectics in transitional South Africa. International Journal of Intercultural Relations, 27, 189-207. 
Worrell, F. C. (2000). Validity study of scores on the Multigroup Ethnic Identity Measure based on a sample of academically talented adolescents. Educational and Psychological Measurement, 60, 439-447. 
Table 1

Correlations among Measures of Racial Attitudes and Spiritual Orientation Disaggregated by Participant Race.

\begin{tabular}{|c|c|c|c|c|c|}
\hline & SRS & AWS & SB & SA & SF \\
\hline \multicolumn{6}{|l|}{$\underline{\text { Racial Attitudes }}$} \\
\hline Subtle Racism Scale & - & -.11 & $-.17^{*}$ & .05 & $.20 * *$ \\
\hline Anti-White Scale & -.12 & - & $.18^{* *}$ & $-.17 * *$ & .01 \\
\hline \multicolumn{6}{|l|}{ Spiritual Orientation } \\
\hline General Beliefs & $-.14^{*}$ & $-.25 * *$ & - & $-.33^{* *}$ & $.26 * *$ \\
\hline Alienation & .10 & $-.31 * *$ & $-.55^{* *}$ & - & $-.25 * *$ \\
\hline Fundamentalism & .10 & .03 & .07 & $-.16^{*}$ & - \\
\hline
\end{tabular}

Note. Correlations with Black and so-called Coloured participants are reported above the diagonal, and correlations with White participants are reported below the diagonal. SRS = Subtle Racism Scale, AWS = Anti-White Scale, SB = Spiritual Beliefs, SA = Spiritual Alienation, SF = Spiritual Fundamentalism. $\quad * p<.05, * * p<.01$ 
Table 2

Regression Model Predicting Subtle Racist Attitudes with Participant Race and Participant Spiritual Beliefs.

Measure

$t$

$p$

Step 1

Participants’ Race

.40

8.8

$<.001$

Step 2

Participants’ Race

.43

9.3

$<.001$

Spiritual Beliefs

.07

1.3

.18

Spiritual Alienation

.11

2.3

.02

Spiritual Fundamentalism

.16

3.5

$<.001$

Step 3

Participants’ Race

.75

1.6

.12

Spiritual Beliefs

.41

2.7

.008

Spiritual Alienation

.25

1.7

.10

Spiritual Fundamentalism

.26

1.9

.06

Spiritual Beliefs x Race

1.0

2.4

.02

Spiritual Alienation x Race

.21

1.6

.25

Spiritual Fundamentalism x Race

.23

1.1

.41 
Table 3

Regression Model Predicting Anti-White Sentiment with Participant Race and Participant Spiritual Beliefs.

Measure

$\beta$

$t$

$p$

Step 1

Participants’ Race

.41

9.2

$<.001$

Step 2

Participants’ Race

.45

10.1

$<.001$

Spiritual Beliefs

.13

2.6

.009

Spiritual Alienation

$-.17$

$-3.6$

$<.001$

Spiritual Fundamentalism

$-.04$

$-0.8$

.42

Step 3

Participants’ Race

.67

1.4

.16

Spiritual Beliefs

.05

0.3

.75

Spiritual Alienation

$-.02$

$-0.2$

.87

Spiritual Fundamentalism

$\begin{array}{ll}-.11 & -0.8\end{array}$

.43

Spiritual Beliefs x Race

.24

0.6

.57

Spiritual Alienation x Race

$-.17 \quad-1.0$

.34

Spiritual Fundamentalism x Race

.17

0.6

.55 